\title{
Sound intensity mapping of an engine dynamometer
}

\author{
M.S.M. Sani ${ }^{1,2^{*}}$, M.M. Rahman',2, M.Z. Baharom ${ }^{1}$ and I. Zaman ${ }^{3}$ \\ ${ }^{1}$ Faculty of Mechanical Engineering, Universiti Malaysia Pahang, \\ 26600 Pekan, Pahang, Malaysia \\ *Email: mshahrir@ump.edu.my \\ Phone: +6094246325; Fax: +609424622 \\ ${ }^{2}$ Automotive Engineering Centre, Universiti Malaysia Pahang, \\ 26600 Pekan, Pahang, Malaysia \\ ${ }^{3}$ Department of Engineering Mechanics, \\ Faculty of Mechanical and Manufacturing Engineering, \\ Universiti Tun Hussein Onn Malaysia, \\ 86400 Parit Raja, Batu Pahat, Johor, Malaysia
}

\begin{abstract}
This paper presents an investigation of the noise source identification (NSI) in a diesel engine at different engine speeds. An experiment was conducted utilizing an eddy current dynamometer with a sound intensity mapping method for the engine speed range of $1500 \mathrm{rpm}$ to $2000 \mathrm{rpm}$. The noise source of the flywheel cover and manifold are presented. It can be observed that the critical cut-off frequency is $1250 \mathrm{~Hz}$. The sound level powers are within the range of $86.42 \mathrm{~dB}$ to $96.34 \mathrm{~dB}$ in varying engine speeds. Further, the noise level is found to be increasing with engine speed. Another main source of vibration is engine mounting, which has a significant effect on noise level due to the engine's structural vibration transfer and noise radiation behavior with respect to the excitation mechanism. The noise power level for mounting is within the range of $77.17 \mathrm{~dB}$ to $89.96 \mathrm{~dB}$ for an engine speed of $1500 \mathrm{rpm}$ to $2000 \mathrm{rpm}$. This method can be applied on-site rather than in an anechoic chamber as long as the background noises are stationary. The project delivers a reliable input for the engineering practice to reduce engine noise level.
\end{abstract}

Keywords: Sound intensity; engine speed; engine dynamometer; noise source.

\section{INTRODUCTION}

Currently, noise reduction has become the main target of new engine development. It is very important to investigate the entire system of noise generation. Ranking of noise generation is essential for designing an engine with low noise levels [1-3]. Engine noise is caused by several excitations or sources of noise, such as combustion, turbo charger, piston slap, valve mechanism, fuel pumps, gears, and inertia forces. A method of noise source identification using the sound intensity technique has been determined for a front-engine [4]. It was found that the surface integration using sound intensity is the simple and most accurate method of determining the noise source. Results have shown different surfaces at different rotation speeds make a different contribution to engine noise. Furthermore, the vibration of front timing gear cover and oil sump are the main contributing factors to front-engine noise. The radiated noise source identification of a six-cylinder construction diesel engine were identified using two methods: lead 
covering and surface vibration technique [2, 5-7]. The sound power level of these components and their contribution to total acoustic power are determined with the lead covering method in a semi-anechoic chamber. The surface vibration technique is determined by the sound power level of various components through the mean square area average vibration. It was concluded that results from both methods agreed well and the effectiveness in the engineering field was verified. Noise generated by cylinder pressure was studied using multipoint coherent power analysis [1]. Cylinder pressure probes were mounted on all engine cylinders. Partial coherence functions were used to analyze the contribution of the cylinder pressures to the measured engine surface velocities. The effect of different fuels, diesel and gas, was studied by comparing cylinder pressures, measured vibrations, and sound power levels. The measurements clearly show that the noise level of gas engines is much lower. It is obvious that the combustion process is one reason and another is the fuel pumps that cause torque variation to the gear. The authors concluded that the cylinder pressure ripple of the diesel combustion seems to be the origin for the higher frequency content above $3 \mathrm{kHz}$.

Coherent power spectrum analysis is used for the identification of complex diesel engine noise source [8]. In the investigation of noise sources, the hierarchy and judgment tree are presented. The result reveals that the noise of the low frequency belt is mainly machinery noise from the oil pump, gear, and valve mechanisms. However, the noise of the high frequency belt is from combustion and oil pan. A modern technique of signal processing - cepstrum analysis method-was employed to analyze the noise and vibration signals of a diesel engine, which separates and extracts periodic source signals [9]. The advantage of this method is its capacity to identify the contribution of each component to the spectrum with the characteristic of non-harmonic order. The result indicates that the cepstrum analysis method can effectively extract source signals from the complex spectrum waveform, thereby facilitating the identification of noise and vibration sources. Sound intensity mapping was applied to identify the reduction of engine noise in a single cylinder air-cooled diesel engine [10]. The result clearly indicates that it is possible to reduce engine noise to the tune of at least $1.5 \mathrm{~dB}$ by modifying the component that contributes most noise. An extensive review paper of noise source identification research is presented in Gin and Haddad [11]. The authors comprehensively reviewed the method of noise source identification such as sound intensity, beamforming, spherical beamforming, and acoustic holography. The paper provides guidelines to help engineers choose a suitable technique based on the frequency range of interest, distance from the measurement array to the test object, and the required resolution. A laser vibrometer is applied to the diesel engine for the identification of the noise source associated with its structural vibration [12]. The vibration maps of the four accessible investigated surfaces around the engine are determined. The motored condition is investigated for different engine speeds in order to quantify the mechanical noise associated with the rotating components and finally to compare with the overall noise in the firing condition. Although a number of investigations and studies have been conducted, to the best of our knowledge and according to existing literature, the best method to investigate noise source identification is still lacking. Therefore, this research focuses on noise source identification by intensity mapping and noise level for a two-stroke petrol engine in a semi-anechoic chamber. The determination of sound power levels of noise sources using sound intensity mapping according to ISO 9614-1[13], ISO 9614-2[14], and ISO 9614-3[15]. The noise source location will be identified based on noise mapping. The noise level that is acceptable for human comfort will be recommended. 


\section{EXPERIMENTAL SETUP}

\section{Mesh Test Rig}

The dimension of the rig used is $135 \mathrm{~cm} \times 100 \mathrm{~cm}$. The dimension of this rig is more than enough for the longest side of the engine dynamometer. The mapping size of each section of the rectangle is $10 \mathrm{~cm} \times 10 \mathrm{~cm}$ based on the International Standard ISO/DIS 9614-1. Each small rectangle functions as a discrete point to determine the sound power levels of noise sources using sound intensity. A rigid test rig using nuts and bolts as connections is used to ensure that noise can be measured at the right coordinates.

\section{Experimental Procedure}

Analyzing the noise generation from the engine dynamometer requires a proper setup before the experiment can be conducted. Figure 1(a) depicts the apparatus setup used in the experiment including the Bruel and Kjaer intensity probe, laptop, calibrator, and front-end signal analyzer. The mesh test rig is located $1 \mathrm{~m}$ on the side of the engine dynamometer, as shown Figure 1(b).

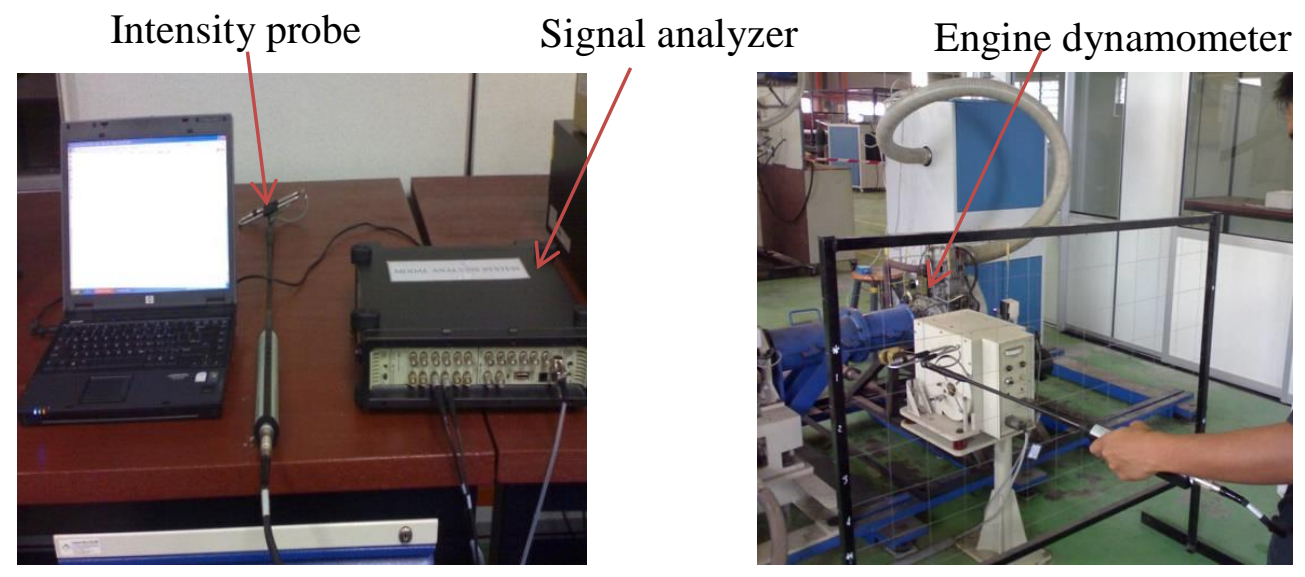

(a)

(b)

Figure 1. (a)Apparatus of measuring sound intensity (b) Test rig set up.

The calibration for the microphone is done in accordance with the calibration chart from Brüel \& Kjær type 4297. The microphone was calibrated until it attains the sound power level of approximately $94.00 \mathrm{~dB}$. Initially, an investigation was conducted to see the difference between the 70, 96, and 150 averages. Although there was some difference among the intensity measurement for these averages, due to the engine condition and location, 96 averages were chosen as a set point for the left and right sides of the engine dynamometer as a set point for the remainder of the testing. For the front and rear sides of the engine dynamometer, 15 averages were used in order to make it easier to identify the part of the engine that contributes noise. After intensity mapping at the engine dynamometer was completed, the experiment was continued in the part that contributed significant noise. After several tests were conducted, it was revealed that the engine itself was a significant source of vibration and noise in the engine test cell. Therefore, the scope of the research became smaller and was focused only on the engine part. For the engine part, a set of 15 points was given for each surface to obtain the 
noise intensity of different components such as the intake and exhaust manifold, the left and right sides, and the left side of the engine valley.

Noise measurements were conducted at the front, rear, and at both sides of the engine according to the SAE recommendation for microphone positions. Noise measurements were made at 1000, 1500, 2000, and $2500 \mathrm{rpm}$ at full load. Figures 2 illustrates the investigations that were conducted using the sound intensity technique for each side or view of the engine dynamometer. The noise analysis can be interpreted by looking at the color of the contour graph to determine which part is a major source of noise by using post processing software, Pulse Labshop (11.1). A graph depicting amplitudes versus frequency is used to identify which location has a high decibel reading.

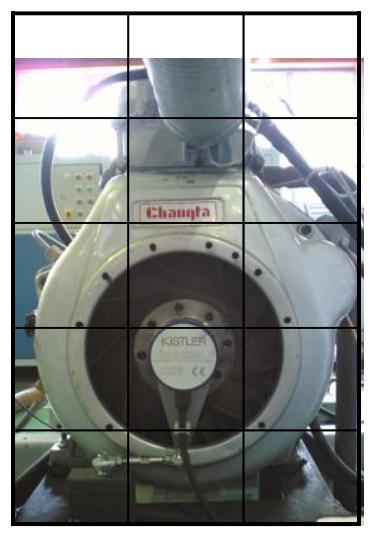

(a) Front view

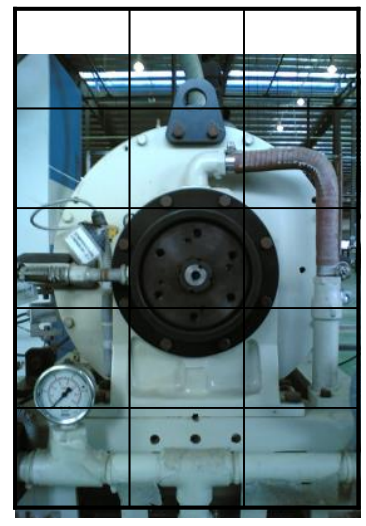

(b) Rear view

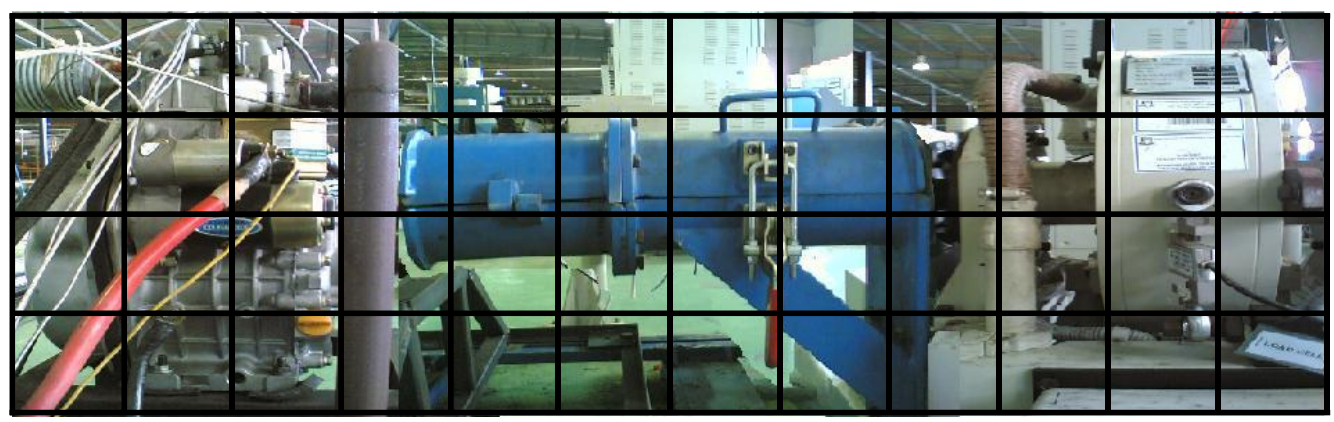

(c) Right view

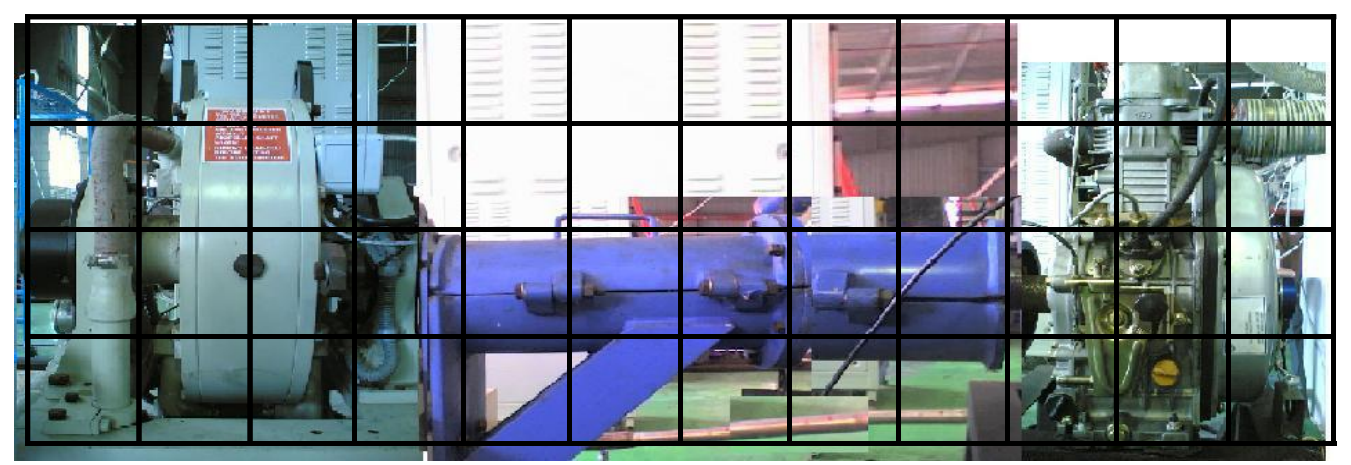

(d) Left view

Figure 2. Different view of experimental set up of sound intensity technique. 


\section{MATHEMATICAL MODELING}

Sound intensity at any point in a sound field in an interest direction $x$ can be expressed as Eq. (1).

$$
S I_{x}=\frac{1}{T} \int_{0}^{T} h(t) w_{x}(t) d t
$$

where $T$ is a sufficiently long averaging time, and $h(t)$ and $w_{x}(t)$ are instantaneous sound pressures and particle velocity in the direction of $x$, respectively. The sound pressure at the midpoints of two microphones can be determined by taking the average of two sound pressure signals, as shown in Eq. (2):

$$
h(t)=\frac{h_{1}(t)+h_{2}(t)}{2} .
$$

The velocity of the particles at midpoint can be obtained by using Euler's equation for a zero mean velocity medium, as shown in Eq.:

$$
w_{x}(t)=-\int \nabla h(t) d t \approx-\frac{h_{2}(t)-h_{1}(t)}{j \omega \rho \Delta x} .
$$

By using Fourier transforms, sound intensity can be summarized as shown in Eq. (4):

$$
S I_{x}(\omega)=\frac{\operatorname{Im}\left[K_{12}(\omega)\right]}{\omega \rho \Delta x}
$$

where $K_{12}(\omega)$ is the one-sided cross power spectrum density function between microphone channels 1 and 2, $\omega$ is the angular frequency, $\rho$ is the air density, and $\Delta x$ is the separation distance between the two microphones.

\section{RESULTS AND DISCUSSION}

\section{Engine Noise}

In this study, investigations were made using the sound intensity technique for each side of an engine dynamometer. This section presents the results of the experiment. A weighted one-third octave band sound power level originating from different parts of the unit were determined from sound intensity measurements made on different parts of the device under test and for different engine speeds. In order to analyze and interpret the results produced by the CPB analyzer that is presented on the screen of a sound intensity analyzer, sound power level can also be determined by examining the color of the contour graph to identify the part that is a major source of noise. As shown by the color indicator on the right side of the picture, the sound power level ranged from $75 \mathrm{~dB}$ to $91 \mathrm{~dB}$. Instead of positive values, negative values are also taken into account in these discussions, where the negative intensity indicated that there was a sound coming from the back of the probe. Figure 3 presents the contour plot of noise from the engine dynamometer. The noise source of flywheel cover and manifold are presented on the 
rear side of contour plot. Other sources of vibration are engine mounting, which significantly affects the noise level due to the engine's structural vibration transfer, and noise radiation behavior with respect to the excitation mechanism.
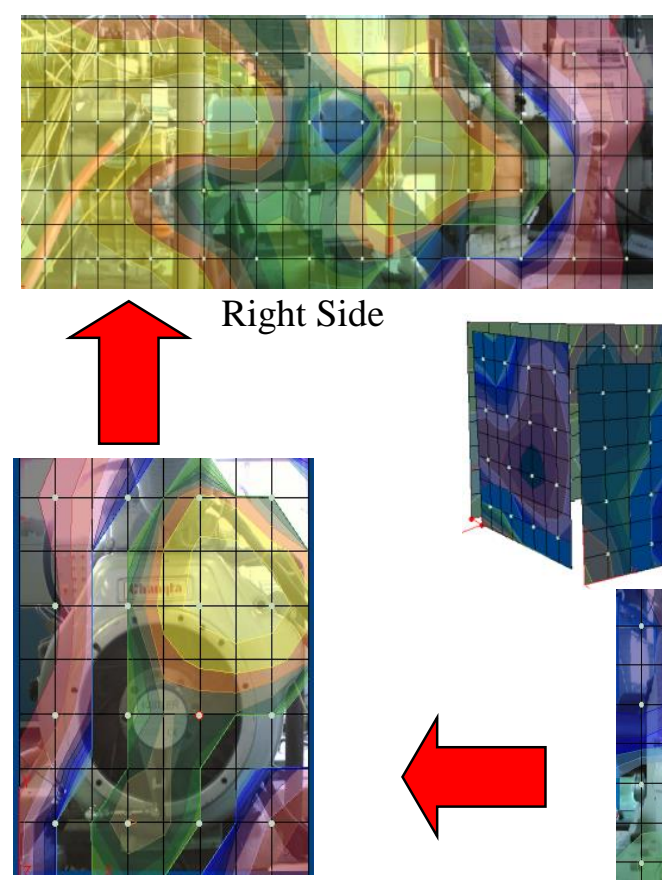

Front Side

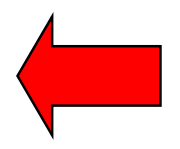

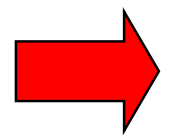

Rear Side
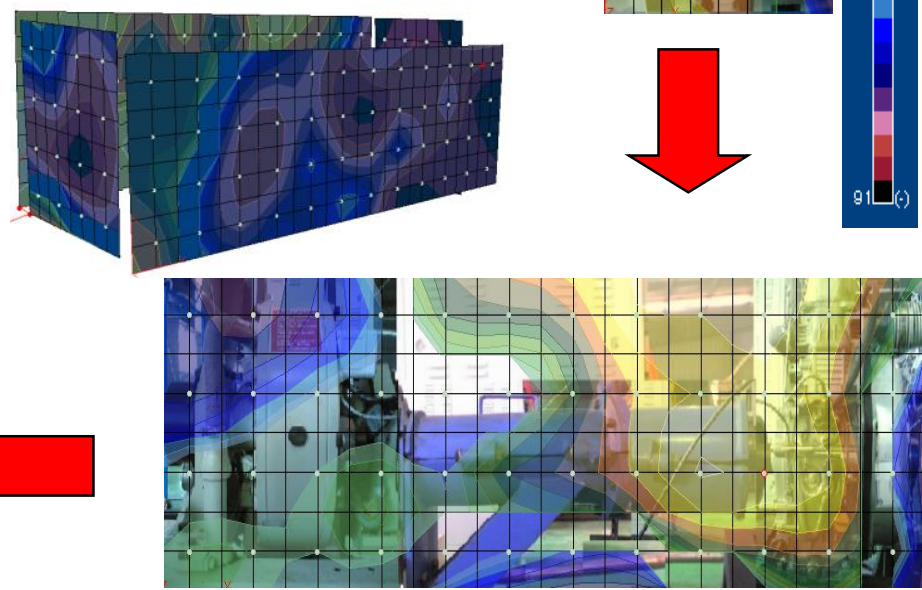

Left Side

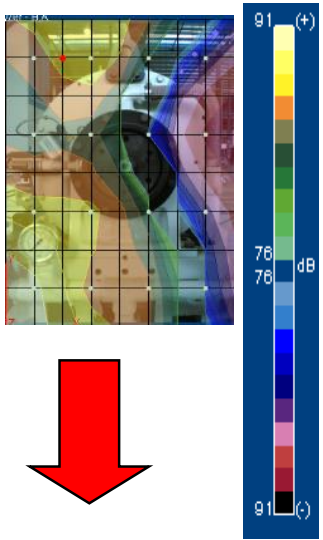

Figure 3. Contour plot of noise from the engine dynamometer.

Table 1 presents the sound power level on the right side of the engine at different speeds of the engine dynamometer. Therefore, in terms of overall engine dynamometer noise detection, an effective method to identify major noise sources in the right side of the engine dynamometer during operation was essential. Figure 4 graphically depicts the noise level value on different sides with varying engine speeds. The engine dynamometer speed at $2500 \mathrm{rpm}$ was the highest average sound power produced with the value of $88.6 \mathrm{~dB}$. Others for the front, rear, and left side the value is $80 \mathrm{~dB}, 74.2 \mathrm{~dB}$, and $79.5 \mathrm{~dB}$ respectively.

Table 1. Sound power level for each side of the engine dynamometer.

\begin{tabular}{rcccc}
\hline Engine & \multicolumn{4}{c}{ Location of Sound Power Level } \\
\cline { 2 - 5 } $\begin{array}{r}\text { Speed } \\
(\text { RPM })\end{array}$ & Front $(\mathrm{dB})$ & Rear $(\mathrm{dB})$ & Left $(\mathrm{dB})$ & Right $(\mathrm{dB})$ \\
\hline 1000 & 83.58 & 71.10 & 71.30 & 82.90 \\
1500 & 74.40 & 71.60 & 72.40 & 83.00 \\
2000 & 77.20 & 75.50 & 79.00 & 86.30 \\
2500 & 80.00 & 74.20 & 79.50 & 88.60 \\
\hline
\end{tabular}




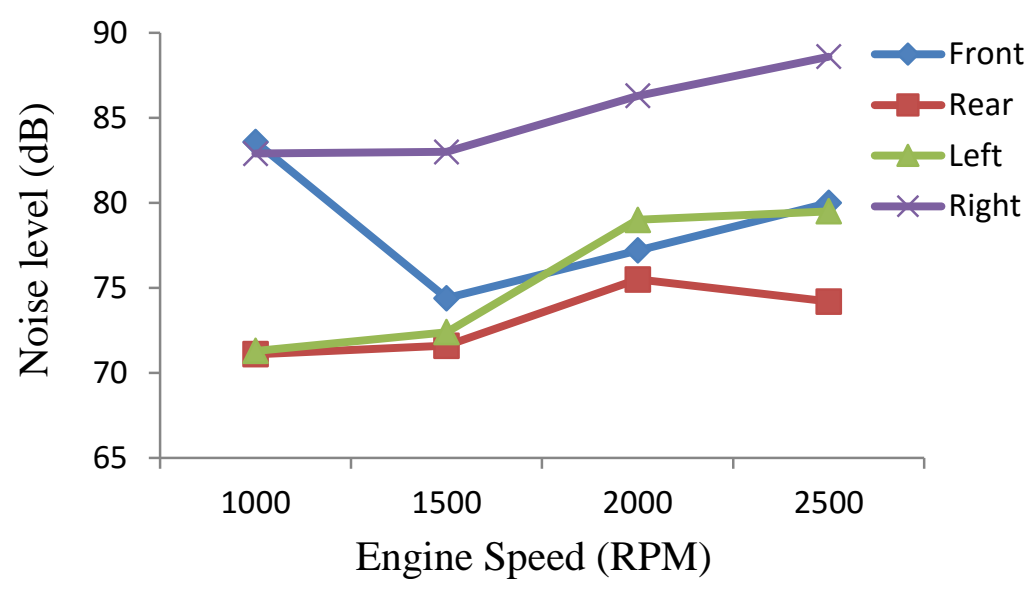

Figure 4. Sound power level versus engine speed.

Figure 5 presents a contour plot of the sound power level produced on the right side of the engine dynamometer. Sound power levels were measured at 20 points on the right side of the engine dynamometer, as shown in Table 2. The highest sound power produced during the test was $78.55 \mathrm{~dB}$ at point 6 and the lowest value at point 14 was $67.92 \mathrm{~dB}$. The red oval shape indicates the part of the engine dynamometer that is a significant source of noise based on the contour color produced.

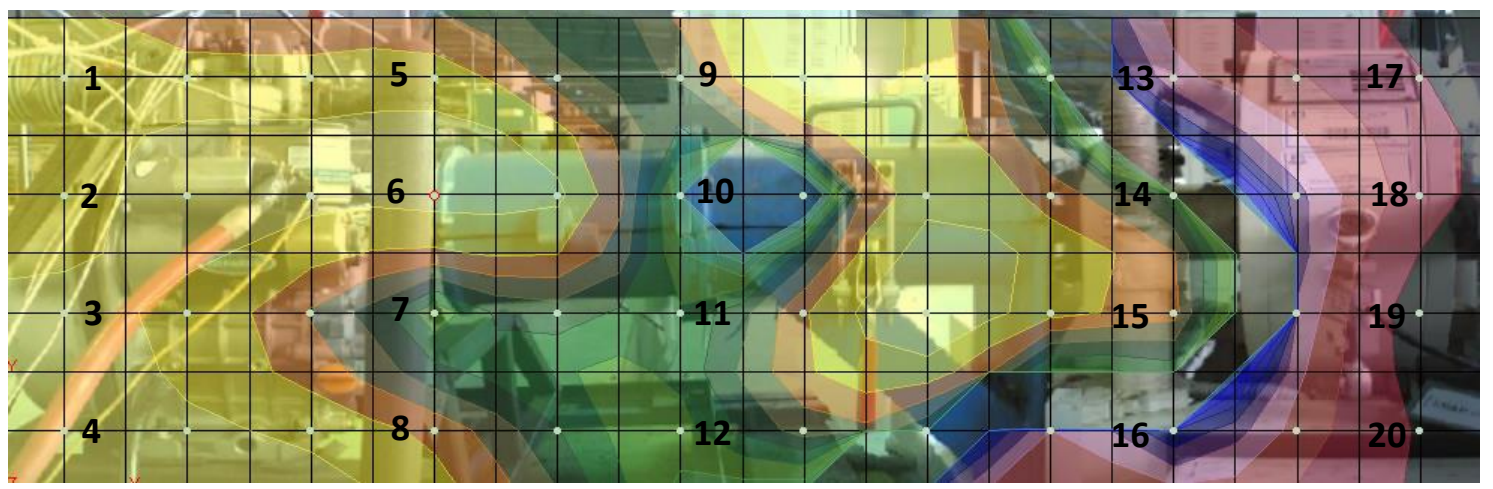

Figure 5. Contour plot of the sound power level produced on the right side of an engine dynamometer.

Table 2. Sound power level produced on the right side of an engine dynamometer.

\begin{tabular}{cccc}
\hline Location & Sound Power Level $(\mathrm{dB})$ & Location & Sound Power Level $(\mathrm{dB})$ \\
\hline 1 & 77.38 & 11 & 72.77 \\
2 & 76.97 & 12 & 72.10 \\
3 & 78.54 & 13 & 73.73 \\
4 & 79.23 & 14 & 67.92 \\
5 & 77.05 & 15 & 70.69 \\
6 & 78.55 & 16 & 69.84 \\
7 & 74.82 & 17 & 76.06 \\
8 & 77.73 & 18 & 71.29 \\
9 & 74.03 & 19 & 75.60 \\
10 & 78.36 & 20 & 72.08 \\
\hline
\end{tabular}


Figure 6 presents the contour diagram of the sound level produced on the left side of the engine dynamometer at the 24-points location. The values of sound power level at 24 points are presented in Table 3. The highest value of sound power produced on the left side of the engine dynamometer is $71.72 \mathrm{~dB}$ at point 19 and the lowest value is $48.52 \mathrm{~dB}$ at point 12 . The oval shape indicates that the engine area is the part that contributes the most noise based on the plotted color contour. The results reveal that the engine itself is the only significant source of vibration and noise in the engine test cell. Therefore, excessive movement and noise levels in the cell must be avoided and the design of alarm signals should take into account in-cell noise levels [16]. Secondary sources such as the ventilation system, pumps, and circulation systems of the engine dynamometer are usually swamped by the effects of the engine.

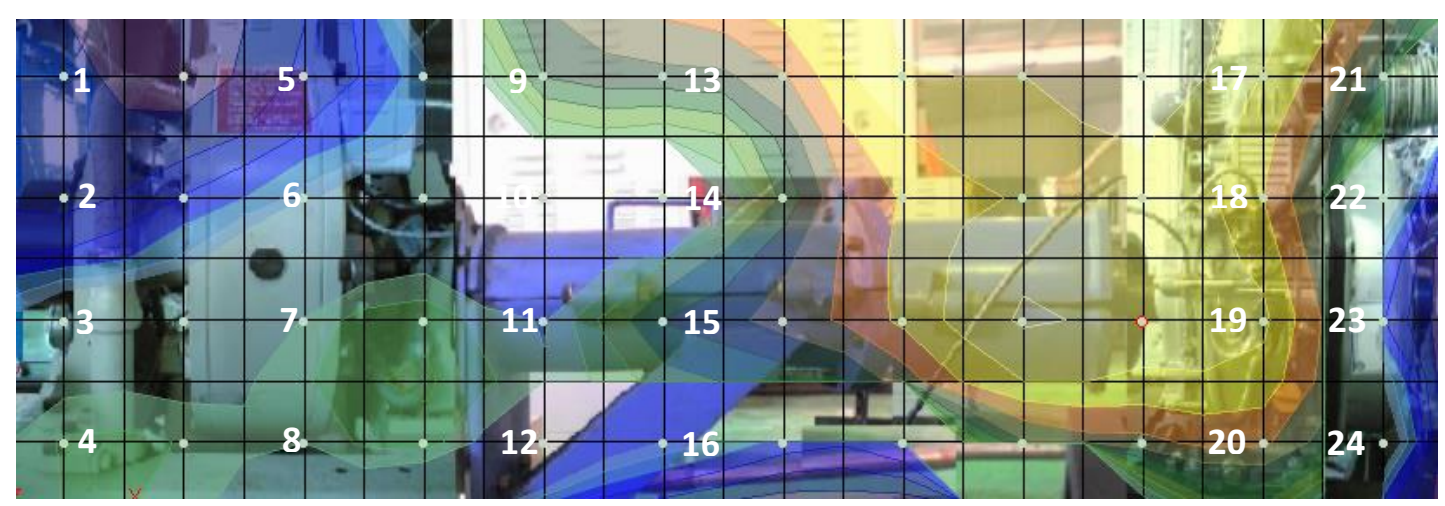

Figure 6. Contour plot of the sound power level produced on the left side of the engine dynamometer.

Table 3. Sound power level produced on the left side of the engine dynamometer.

\begin{tabular}{cccc}
\hline Location & Sound Power Level $(\mathrm{dB})$ & Location & Sound Power Level $(\mathrm{dB})$ \\
\hline 1 & 64.99 & 13 & 66.84 \\
2 & 64.64 & 14 & 62.95 \\
3 & 54.25 & 15 & 66.20 \\
4 & 59.75 & 16 & 61.54 \\
5 & 63.60 & 17 & 71.49 \\
6 & 58.68 & 18 & 70.13 \\
7 & 58.37 & 19 & 71.72 \\
8 & 58.04 & 20 & 65.08 \\
9 & 64.10 & 21 & 69.90 \\
10 & 51.25 & 22 & 68.46 \\
11 & 57.82 & 23 & 70.37 \\
12 & 48.52 & 24 & 67.33 \\
\hline
\end{tabular}

\section{CONCLUSIONS}

In this paper, the sound intensity method was employed to identify the noise source of the engine dynamometer. This method is very simple and the most accurate to determine the noise source of an engine dynamometer. Higher engine speeds contribute to higher noise levels. The results of different sides of the engine dynamometer at different engine speeds indicate that both sides make a different contribution to engine noise. The result yields the same trend of sound power produced by the diesel engine exhaust as that in existing literature. 


\section{ACKNOWLEDGEMENTS}

The authors would like to be obliged to Universiti Malaysia Pahang for providing laboratory facilities and financial assistance under project no. RDU 130392.

\section{REFERENCES}

[1] Lamula L, Saine K, Saarinen K, Hyrynen H. Cylinder pressure generated noise of medium speed diesel engine. Proceedings of Joint Baltic-Nordic Acoustics; 2008. p. 1-5.

[2] Jha SK, Sharma A. Optimal automobile muffler vibration and noise analysis. International Journal of Automotive and Mechanical Engineering. 2013;7:86481.

[3] Magaswaran K, Phuman Singh AS, Hassan MZ. A new method in the identification of noise and vibration characteristics of automotive disk brakes in the low frequency domain. International Journal of Automotive and Mechanical Engineering. 2014;9:1564-77.

[4] JunHong Z, Bing H. Analysis of engine front noise using sound intensity techniques. Mechanical Systems and Signal Processing. 2005;19:213-21.

[5] Liu Y-H, Hao Z-Y, Bi FR, Fu L-H, Han S-T. Engine noise source identification with different methods. Journal Tianjin University. 2002;8:174-7.

[6] Ab Latif N, M. Rus AZ. Vibration transmissibility study of high density solid waste biopolymer foam. Journal of Mechanical Engineering and Sciences. 2014;6:772-81.

[7] Shan CW, Ghazali MI, Idris MI. Improved vibration characteristics of flexible polyurethane foam via composite formation. International Journal of Automotive and Mechanical Engineering. 2013;7:1031-42.

[8] Shu G, Liang X. Identification of complex diesel engine noise sources based on coherent power spectrum analysis. Mechanical Systems and Signal Processing. 2007;21:405-16.

[9] Liang X, Yang K, Shu G, Gong I, Mei Y, Wang Y. The identification of noise source in diesel engine based on the cepstrum analysis of sound and vibration signals. SAE Technical Paper. 2012.

[10] Chaudhari SB, Lomte SV. Noise source identification and reduction in single cylinder diesel engine. Journal of Industrial Science. 2014;1.

[11] Gin KB, Haddad K. Noise source identification technique: simple to advanced applications. Proceedings of Acoustics Conference2012. p. 1781-6.

[12] Daniela S. Vibro-acoustic characterization of direct injection diesel engine by the use of a scanning laser vibrometer technique. Proceedings of International Conference Sound and Vibration. 2007;14.

[13] (ISO) IOfS. Determination of sound power levels of noise sources using sound intensity Part 1: Measurement at Discrete Points; 1993.

[14] (ISO) IOfS. Determination of sound power levels of noise sources using sound intensity Part 2: Measurement by Scanning; 1996.

[15] (ISO) IOfS. Determination of sound power levels of noise sources using sound intensity Part 3: Precision Method for Measurement by Scanning; 2002.

[16] Martyr AJ, Plint MA. Engine testing: The design, building, modification and use of powertrain test facilities. Oxford, United Kingdom: Butterworth-Heinemann; 2012. 